\title{
Treatment of Breast Tumor Cells In Vitro with the Mitochondrial Membrane Potential Dissipater Valinomycin Increases ${ }^{18}$ F-FDG Incorporation
}

\author{
Tim A.D. Smith ${ }^{1}$ and Morgan G. Blaylock ${ }^{2}$ \\ ${ }^{1}$ John Mallard PET Centre, School of Medical Sciences, University of Aberdeen, Foresterhill, Aberdeen, Scotland; and ${ }^{2}$ Institute of \\ Medical Sciences, School of Medical Sciences, University of Aberdeen, Foresterhill, Aberdeen, Scotland
}

\begin{abstract}
Mitochondrial membrane potential is essential for adenosine triphosphate (ATP) synthesis by oxidative phosphorylation, and its abolition is an early event during apoptosis, a type of cell death commonly exhibited by tumor cells responding to treatment. Dissipation of mitochondrial membrane potential can be specifically induced using the $\mathrm{K}^{+}$ion channel-opening agent valinomycin and has been used in this study to determine how the loss of mitochondrial membrane potential could influence ${ }^{18} \mathrm{~F}-\mathrm{FDG}$ incorporation. Methods: MCF-7 cells were treated with valinomycin for $30 \mathrm{~min}$, inducing loss of mitochondrial membrane potential as determined using flow cytometry with the $\mathrm{JC}-1$ probe. ${ }^{18} \mathrm{~F}$ FDG incorporation, the initial rate of $O$-methyl-D-glucose incorporation (a measure of glucose transport), hexokinase activity and subcellular distribution, ATP content using bioluminescence, and lactate production were determined on control and valinomycin-treated cells. Results: A 30-min treatment of MCF-7 cells with $1 \mu \mathrm{mol}$ of valinomycin per liter resulted in absence of red fluorescence from JC-1, indicative of dissipation of mitochondrial membrane potential. ${ }^{18} \mathrm{~F}-\mathrm{FDG}$ incorporation was significantly increased by 30 min of treatment with valinomycin and was still apparent after $3.5 \mathrm{~h}$ of incubation. Hexokinase activity and subcellular distribution were not significantly different between control cells and cells treated for $30 \mathrm{~min}$ with valinomycin. Glucose transport was moderately though significantly increased, and lactate production was also increased. Conclusion: Loss of mitochondrial membrane potential is associated with increased ${ }^{18} \mathrm{~F}-\mathrm{FDG}$ incorporation, glucose transport, and lactate production.
\end{abstract}

Key Words: ${ }^{18}$ F-FDG; mitochondria; membrane potential; glucose transport; lactate

J Nucl Med 2007; 48:1308-1312

DOI: 10.2967/jnumed.107.041665

\section{$\mathbf{P}$} ET using the tracer ${ }^{18} \mathrm{~F}-\mathrm{FDG}$ is becoming a routine tool in the early detection of tumor response to therapy. Tumors responding to therapy generally show a decreased incorporation of ${ }^{18} \mathrm{~F}-\mathrm{FDG}$ within the first 1 or 2 cycles of chemo-

\footnotetext{
Received Mar. 12, 2007; revision accepted May 7, 2007.

For correspondence or reprints contact: Tim A.D. Smith, PhD, PET Centre, Department of Biomedical Physics, School of Medical Sciences, University of Aberdeen, Foresterhill, Aberdeen AB25 2ZD, Scotland.

E-mail: t.smith@biomed.abdn.ac.uk

COPYRIGHT @ 2007 by the Society of Nuclear Medicine, Inc.
}

therapy (1), a result believed to reflect a decreased number of viable tumor cells (2). However, several studies that have determined ${ }^{18} \mathrm{~F}$-FDG incorporation early after therapy, during cell response to damage, have shown that ${ }^{18} \mathrm{~F}$-FDG uptake can be increased in tumors that are subsequently shown to respond well to treatment (3-5) and in cell lines responding to ionizing radiation or chemotherapy $(6-11)$.

It has been reported that an early increase in ${ }^{18} \mathrm{~F}-\mathrm{FDG}$ incorporation after treatment of cells using ionizing radiation corresponds to an increased level of apoptosis, a form of cell death frequently associated with response to cytotoxic anticancer treatment, including radiation therapy (12). Furuta et al. (13) determined ${ }^{18} \mathrm{~F}-\mathrm{FDG}$ uptake by xenografts 2-6 $\mathrm{h}$ after irradiation and found that the most radiationsensitive tumor, an ependymoblastoma, which showed high levels of apoptosis, exhibited enhanced ${ }^{18}$ F-FDG uptake after irradiation when compared with nonirradiated controls. Two other tumors that were far less sensitive to radiation and exhibited only low levels of apoptosis did not show enhanced ${ }^{18}$ F-FDG uptake.

Apoptosis involves the loss of mitochondrial membrane potential followed by mitochondrial membrane swelling and release of cytochrome c (14). Loss of mitochondrial membrane potential is associated with changes in the energy status of cells (15-18) and so is likely to influence the incorporation of ${ }^{18} \mathrm{~F}-\mathrm{FDG}$. The mitochondrial membrane can be depolarized by treating cells with the selective $\mathrm{K}^{+}$ion channel-opening agent valinomycin. To determine whether loss of mitochondrial membrane potential could contribute to clinical and experimental findings regarding early increases in ${ }^{18} \mathrm{~F}$-FDG incorporation after therapy, we measured ${ }^{18} \mathrm{~F}-\mathrm{FDG}$ incorporation by MCF-7 cells treated with valinomycin. We also determined how dissipation of the mitochondrial membrane potential modulated glucose transport, hexokinase activity, adenosine triphosphate (ATP) concentration, and lactate production.

\section{MATERIALS AND METHODS \\ Materials}

All chemicals were acquired from Sigma-Aldrich Chemical Co. unless otherwise stated. 


\section{Cells and Treatment}

MCF-7 cells were grown in Dulbecco's modified Eagle medium (Invitrogen) supplemented with $10 \%$ fetal bovine serum, 50 units of penicillin per milliliter, and $50 \mu \mathrm{g}$ of streptomycin per milliliter (Invitrogen). The cells were grown in $75-\mathrm{cm}^{2}$ tissue culture flasks in a $\mathrm{CO}_{2}$ incubator $\left(5 \% \mathrm{CO}_{2}: 95 \%\right.$ air $)$ at $37^{\circ} \mathrm{C}$ and routinely passaged when confluent. Before each experiment, cells were seeded in $25-\mathrm{cm}^{2}$ tissue culture flasks. Cells in the requisite numbers of flasks were treated by the addition of new medium containing valinomycin in dimethyl sulfoxide (final concentration, $1 \mu \mathrm{mol} / \mathrm{L}$ ) for $30 \mathrm{~min}$. Control cells received fresh medium containing the same amount of dimethyl sulfoxide vehicle.

\section{${ }^{18}$ F-FDG Incorporation}

Flasks of untreated and treated cells were incubated at $37^{\circ} \mathrm{C}$ with medium containing $1 \mathrm{kBq}$ of ${ }^{18} \mathrm{~F}-\mathrm{FDG}$ per milliliter for $20 \mathrm{~min}$. The medium was then removed, $100 \mu \mathrm{L}$ were frozen for lactate determination, and the flasks were washed 5 times with $6 \mathrm{~mL}$ of ice-cold phosphate-buffered saline (PBS). Cells were then removed by the addition of $0.5 \mathrm{~mL}$ of trypsin and, after the addition of $0.5 \mathrm{~mL}$ of medium, were transferred to a microcentrifuge (Eppendorf) tube. After removal of $200 \mu \mathrm{L}$ for ATP determination, radioactive counts were determined using a well counter. The cells were then pelleted by centrifugation at $400 \mathrm{~g}$ for $5 \mathrm{~min}$ and were washed with $1 \mathrm{~mL}$ of PBS. The washed pellet was dissolved overnight in $\mathrm{NaOH}(1 \mathrm{~mol} / \mathrm{L})$. After neutralization with $\mathrm{HCl}(1 \mathrm{~mol} / \mathrm{L})$, protein content was determined using a bicinchoninic acid protein assay kit according to the manufacturer's instructions (SigmaAldrich). The results were expressed as counts per minute, per milligram of protein.

\section{Glucose Transport}

Glucose transport was determined by measuring the initial uptake of the nonmetabolized glucose analog ${ }^{3} \mathrm{H}-\mathrm{O}$-methyl glucose (OMG) (Amersham). Flasks of cells were incubated with fresh medium containing ${ }^{3} \mathrm{H}-\mathrm{OMG}$ plus $0.1 \mathrm{mmol}$ of OMG per liter for $10 \mathrm{~s}$ (uptake of OMG by MCF-7 cells is linear for at least $30 \mathrm{~s}$ (19)), after which $10 \mathrm{~mL}$ of ice-cold PBS were added and rapidly removed by inverting the flask. Three more rapid washes were performed, and then the cells were detached by incubation with trypsin and, after being neutralized with medium, were thoroughly mixed by working a 1-mL pipette up and down to break up clumps. Half the cell suspension was then added to $5 \mathrm{~mL}$ of Ultima Gold (PerkinElmer) scintillation fluid, and ${ }^{3} \mathrm{H}$ incorporation was determined on a scintillation counter. The other half was centrifuged at $400 \mathrm{~g}$ for $5 \mathrm{~min}$, the supernatant was discarded, and the pellet was resuspended in $1 \mathrm{~mL}$ of PBS. After further centrifugation, the pellet was resuspended in $0.1 \mathrm{~mL}$ of $\mathrm{NaOH}(1 \mathrm{~mol} / \mathrm{L})$. Protein content was then determined as described above.

\section{Hexokinase Activity}

Cell homogenate was prepared and cells fractionated $(20,21)$. Flasks of treated and control cells were harvested by trypsinization and neutralization with medium. They were then placed in microcentrifuge tubes and centrifuged at $400 \mathrm{~g}$ for $5 \mathrm{~min}$ at $4{ }^{\circ} \mathrm{C}$. After the supernatant had been discarded, the pellet was washed with PBS and then resuspended in $100 \mu \mathrm{L}$ of homogenization buffer (Tris/ $\mathrm{HCl}$ [10 mmol/L, pH 7.7], sucrose [0.25 mmol/L], dithiothreitol [0.5 mmol/L], aminohexanoic acid [1 $\mathrm{mmol} / \mathrm{L}]$, and phenylmethylsulfonyl fluoride $[1 \mathrm{mmol} / \mathrm{L}])$. This was transferred to a
1-mL Dounce homogenizer (Fisher Scientific) and homogenized by 10 strokes (up and down while rotating the pestle). The homogenate was then transferred to the original microcentrifuge tube, which was centrifuged at $800 \mathrm{~g}$ for $15 \mathrm{~min}$. The supernatant was transferred to a new microcentrifuge tube, the pellet was washed with $100 \mu \mathrm{L}$ of homogenization buffer, and the centrifugation was repeated. Total hexokinase activity was determined on a $50-\mu \mathrm{L}$ sample. The remainder was centrifuged at $14,000 \mathrm{~g}$ for $10 \mathrm{~min}$ in a microcentrifuge tube to pellet the mitochondria. The supernatant was saved, and the pellet was washed with $100 \mu \mathrm{L}$ of homogenization buffer. The wash was added to the supernatant, and the hexokinase activity was determined on the combined "cytoplasmic" fraction. The mitochondria were resuspended in $70 \mu \mathrm{L}$ of homogenization buffer and used to determine mitochondrial hexokinase activity.

Hexokinase was determined by adding $50 \mu \mathrm{L}$ of homogenate to a cuvette containing Tris/ $\mathrm{HCl}(100 \mathrm{mmol} / \mathrm{L}, \mathrm{pH} 8.0)$, glucose $(10 \mathrm{mmol} / \mathrm{L})$, nicotinamide adenine dinucleotide phosphate $\left(\mathrm{NADP}^{+}\right)$ (0.4 mmol/L), $\mathrm{MgCl}_{2}(10 \mathrm{mmol} / \mathrm{L})$, ATP (5 mmol/L), and glucose-6phosphate dehydrogenase ( 0.15 unit) and by following the production of reduced nicotinamide adenine dinucleotide phosphate $\left(\mathrm{NADP}^{+}\right)$ at $340 \mathrm{~nm}$ in a Helios $\gamma$-Series 2 ultraviolet-visible spectrometer (Thermo Spectronic; Fisher Scientific). Enzyme activity was expressed as $\mathrm{mU} / \mathrm{mg}$ of protein using the extinction coefficient for reduced nicotinamide adenine dinucleotide phosphate of $6.3 \times$ $10^{3} \mathrm{~mol}^{-1} \mathrm{~cm}^{-1}$.

\section{Cytofluorimetric Analysis of Mitochondrial Potential and Annexin Binding}

The membrane potential in MCF-7 cells was measured using the cationic dye JC-1, which exhibits potential-dependent accumulation in mitochondria, indicated by a fluorescence emission shift from green $(\sim 525 \mathrm{~nm})$ to red $(\sim 590 \mathrm{~nm})$. Consequently, mitochondrial depolarization is indicated by a decrease in the redto-green fluorescence-intensity ratio. The percentage of cells that emit only red fluorescence attributable to polarized mitochondrial membranes was determined. One flask of control cells was incubated for 30 min with medium containing the depolarizing compound valinomycin $(1 \mu \mathrm{mol} / \mathrm{L})$ (22). JC-1 was dissolved in dimethyl sulfoxide $(5 \mathrm{mg} / \mathrm{mL})$, and $50 \mu \mathrm{L}$ were added to $10 \mathrm{~mL}$ of medium. Cells were incubated with $2 \mathrm{~mL}$ of medium containing JC-1 for 15 min at $37^{\circ} \mathrm{C}$ and then washed twice with PBS. Cells were then detached with trypsin and, after the addition of medium and centrifugation at $400 \mathrm{~g}$ for $5 \mathrm{~min}$, were resuspended in $0.5 \mathrm{~mL}$ of PBS. They were then analyzed on an LSR Research Flow Cytometer (Becton Dickinson) to detect green fluorescence at excitation/ emission wavelengths of $485 / 530 \mathrm{~nm}$ and red fluorescence at excitation/emission wavelengths of 550/595 nm.

Apoptosis and cell viability were determined by annexin V-FITC binding to exposed phosphatidylserine and propidium iodide uptake using a kit (Sigma-Aldrich) and following the manufacturer's directions.

\section{Determination of Cellular ATP Content and Lactate Production}

Lactate was determined on medium sampled at the end of incubation with ${ }^{18} \mathrm{~F}-\mathrm{FDG}$ using a lactate assay kit (Biovision) and following the manufacturer's instructions. ATP was determined using a bioluminescent somatic cell assay kit (Sigma). Samples were prepared as described under " ${ }^{18}$ F-FDG Incorporation." 


\section{Statistics}

Statistical differences between means were determined using the Student $t$ test and were considered significant if $P$ was less than 0.05 .

\section{RESULTS}

Figure 1 shows the effect of $1 \mu \mathrm{mol}$ of valinomycin per liter on JC-1 fluorescence: a loss of red fluorescence (loss of membrane potential-dependent accumulation in mitochondria) indicative of mitochondrial membrane depolarization. No increase was found in annexin binding or uptake of propidium iodide by cells treated with valinomycin for $40 \mathrm{~min}$.

Treatment with valinomycin for $30 \mathrm{~min}$, shown in Figure 2 , resulted in significantly $(t=5.97, P<0.001)$ increased ${ }^{18} \mathrm{~F}-\mathrm{FDG}$ incorporation by MCF-7 cells. Enhanced uptake
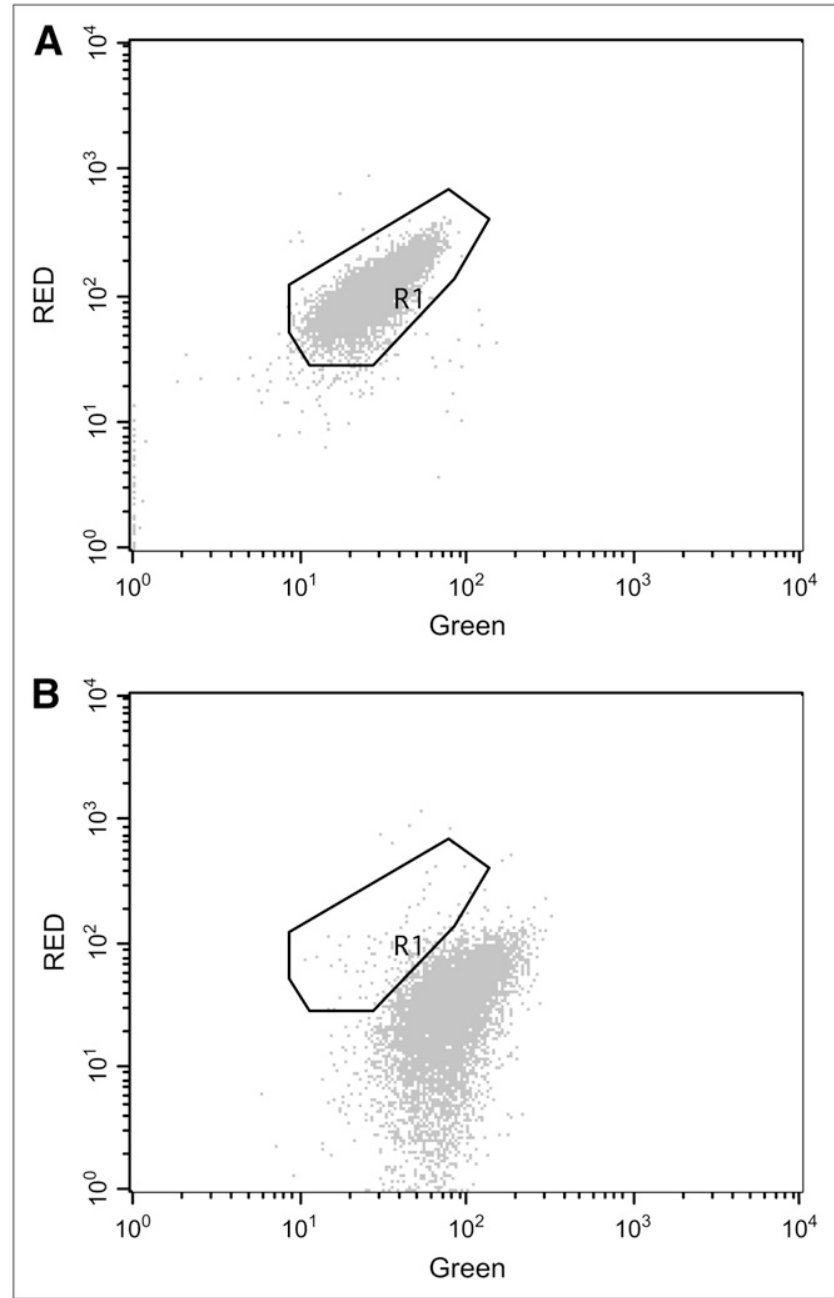

FIGURE 1. Fluorescence of MCF-7 control cells (A) and valinomycin-treated cells (30 $\mathrm{min})(B)$ incubated with mitochondrial membrane potential probe JC-1. $x$ - and $y$-axes are green and red fluorescence, respectively. Valinomycin-treated cells show loss of red fluorescence (loss of membrane potentialdependent accumulation in mitochondria) indicative of mitochondrial membrane depolarization.

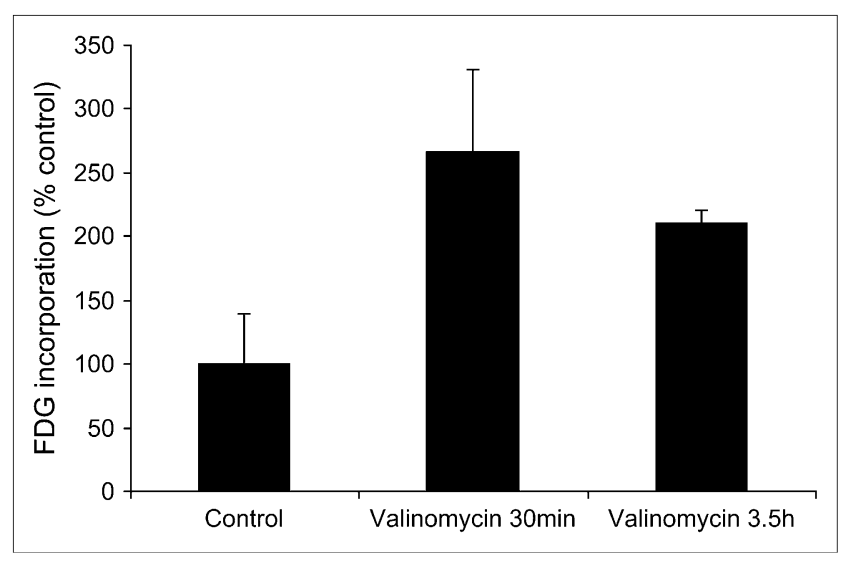

FIGURE 2. ${ }^{18} \mathrm{~F}-\mathrm{FDG}$ incorporation by control MCF-7 cells $(n=$ $7)$ treated for $30 \mathrm{~min}(n=7)$ and $3.5 \mathrm{~h}(n=4)$ with valinomycin (\% control).

was still apparent after $3.5 \mathrm{~h}$ of incubation $(t=4.67, P<$ $0.01)$. The initial rate of OMG transport, shown in Figure 3 (a measure of glucose transport), was significantly increased $(t=3.27, P<0.01)$ by about $25 \%$ in cells treated for 30 min with valinomycin, compared with untreated cells. Figure 4 shows the effects of valinomycin treatment on total hexokinase activity and the percentage of mitochondrial bound hexokinase activity. These effects were not statistically significantly different from those in untreated cells (total activity: $t=0.64$; mitochondrial activity fraction: $t=1.24)$.

Table 1 shows the cellular ATP content and rate of lactate production. ATP content in valinomycin-treated cells was similar to that in control cells $(t=1.78$, not statistically significant), whereas lactate production was significantly increased $(t=4.1, P<0.001)$ in cells treated for $30 \mathrm{~min}$ with valinomycin.

\section{DISCUSSION}

${ }^{18} \mathrm{~F}-\mathrm{FDG}$ incorporation is generally found to be decreased, compared with pretreatment levels, in responding tumors when PET scans are performed a week or so after

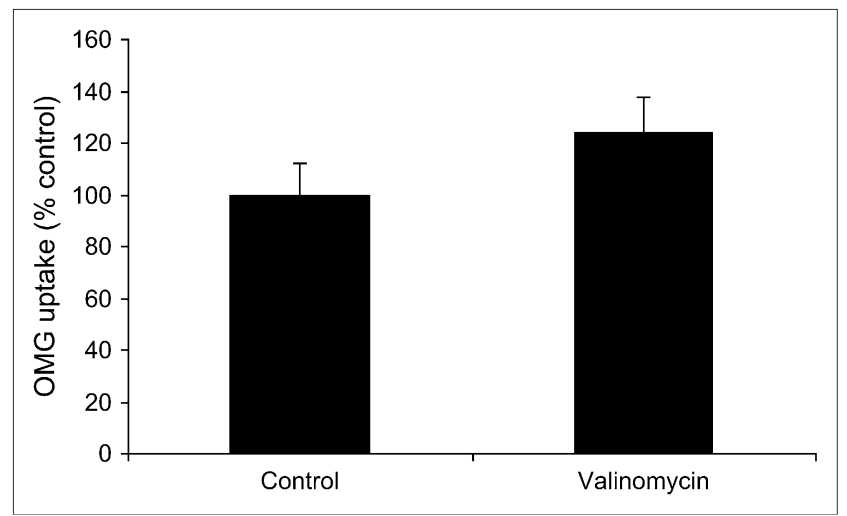

FIGURE 3. Initial rate of OMG uptake by cells treated for 30 min with valinomycin ( $n=7$, treated and controls). 


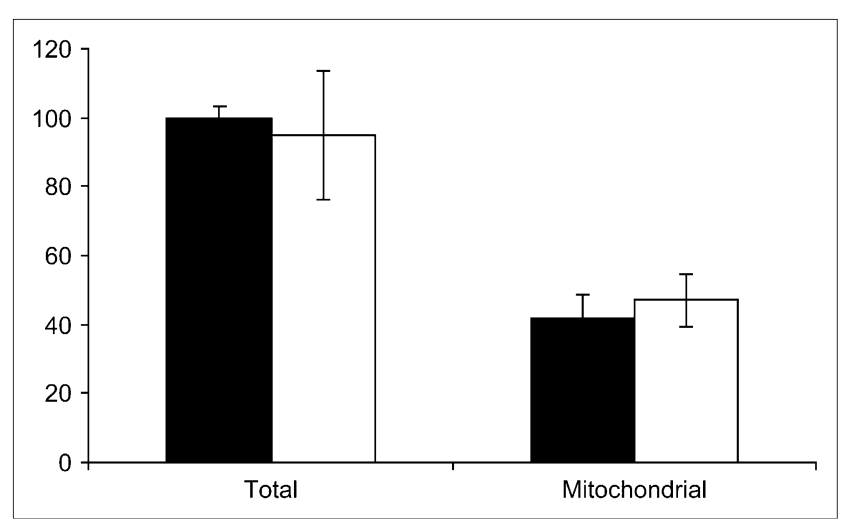

FIGURE 4. Hexokinase activity total (\% control) and mitochondrial hexokinase (\% total activity by cell extracts treated with valinomycin for $30 \mathrm{~min})(n=6$, treated and control).

therapy. However, it has frequently been reported that increased ${ }^{18} \mathrm{~F}$-FDG incorporation shortly after therapy predicts a good response. De Witte et al. (3) determined ${ }^{18} \mathrm{~F}-\mathrm{FDG}$ uptake by gliomas before and $24 \mathrm{~h}$ after treatment with carmustine and found that a hypermetabolic reaction after therapy predicted patient survival. In a study of 8 patients with brain tumors, Maruyama et al. (4) showed increased ${ }^{18} \mathrm{~F}$-FDG uptake $4 \mathrm{~h}$ after treatment with a single radiation dose. Studies of cultured cells have also shown increased ${ }^{18} \mathrm{~F}$ FDG (or ${ }^{3} \mathrm{H}$-deoxyglucose) uptake a few hours after treatment. Fujibayashi et al. (6) showed that treatment of LS180 human colon adenosarcoma cells with 3 or $30 \mathrm{~Gy}$ of radiation resulted in enhanced 2-deoxy-D-glucose uptake between 1 and $4 \mathrm{~h}$ after irradiation. Similarly, Haberkorn et al. (7) observed increased ${ }^{18} \mathrm{~F}$-FDG uptake by MCF-7 cells between 1 and $4 \mathrm{~h}$ after treatment with the apoptosis-inducing phospholipid hexadecylphosphocholine (10) and, in a later study (8), a dose-dependent increase in ${ }^{18} \mathrm{~F}$-FDG incorporation $4 \mathrm{~h}$ after treatment of rat prostate adenocarcinoma cells with the cytidine analog gemcitabine. Higashi et al. (11) treated human ovarian cancer cells with radiation and found increased ${ }^{18} \mathrm{~F}$ FDG incorporation between 0 and $12 \mathrm{~d}$ afterward.

The onset of apoptosis, a mechanism of cell death associated with response to radiation and chemotherapy, involves early loss of mitochondrial membrane potential (14). In this study, we found that ${ }^{18} \mathrm{~F}-\mathrm{FDG}$ incorporation was

TABLE 1

ATP Content and Lactate Production by Control and Treated MCF-7 Cells

\begin{tabular}{lrr}
\hline \multicolumn{1}{c}{ MCF-7 cell group } & \multicolumn{1}{c}{ ATP $^{\star}$} & Lactate $^{\dagger}$ \\
\hline Control & $15.4 \pm 4.6$ & $3.4 \pm 0.98$ \\
Valinomycin-treated (30 min) & $19 \pm 5.8$ & $5.4 \pm 0.95$
\end{tabular}

${ }^{*} \mu \mathrm{g} / \mathrm{mg}$ of protein; $n=15$ for both.

${ }^{\dagger} \mu \mathrm{mol}$ formed/mg of protein/15 $\mathrm{min} ; n=8$ for both. enhanced by depolarization of the mitochondrial membrane in MCF-7 cells by treatment with valinomycin for $30 \mathrm{~min}$ before phosphatidylserine was exposed on the cell surface. Lactate production was also increased, suggesting an increased rate of glycolysis. Several ${ }^{1} \mathrm{H}$ nuclear magnetic resonance studies have reported increased lactate production by tumors both in vivo and in vitro (23-25) during response to treatment. Santini et al. (23) showed increased lactate levels by osteosarcoma cells during the first $24 \mathrm{~h}$ after treatment with radiation. The postherapy increase in lactate production occurred in cells grown both as monolayers and as 3-dimensional microspheroids. Lutz et al. (24) showed that treatment of human colon adenocarcinoma cells (HT-29) with a combination of $\gamma$-interferon and tumor necrosis factor $\alpha$, which was shown to induce apoptosis, caused a time-dependent increase in lactate production between 4 and $15 \mathrm{~h}$ after the addition of treatment. Increased lactate levels have also been detected after treatment of HeLa tumor cells with radiation (25).

${ }^{18} \mathrm{~F}-\mathrm{FDG}$ incorporation can be modulated by changes in the rate of glucose transport, hexokinase activity, and the rate of dephosphorylation by glucose-6-phosphatase. However, MCF-7 cells do not express glucose-6-phosphatase (19). Further, hexokinase activity and its subcellular location were found not to be altered by treatment of cells with valinomycin for $30 \mathrm{~min}$. Glucose transport was significantly increased - an effect that would increase the rate of ${ }^{18} \mathrm{~F}$-FDG uptake. However, the increase of glucose transport was only $25 \%$, whereas the increase in ${ }^{18} \mathrm{~F}-\mathrm{FDG}$ incorporation was over $100 \%$.

The availability of ATP (26) is associated with ${ }^{18} \mathrm{~F}-\mathrm{FDG}$ incorporation, but in the present study we did not find a significant change in cellular ATP content after treatment with valinomycin despite mitochondrial membrane potential's being crucial for the activity of ATP synthase (18). Previous studies have also shown that ATP content can be maintained or even enhanced after treatment with dissipaters of mitochondrial membrane $(15,17,18)$ but not after inhibitors of glycolysis (16). Noda et al. (27) have shown that inhibition of oxidative phosphorylation results in a buildup of reduced nicotinamide adenine dinucleotide in the mitochondria and retrogressively into the cytoplasm, resulting in an enhanced rate of lactate formation (which requires reduced nicotinamide adenine dinucleotide). The increase in lactate production after treating cells with valinomycin, observed in the present study, suggests that ATP synthesis by oxidative phosphorylation is switched to anaerobic synthesis. This change would result in a more rapid glycolytic flux and more incorporation of ${ }^{18} \mathrm{~F}-\mathrm{FDG}$. It is also possible that ATP synthesized in the cytoplasm by glycolysis, rather than by mitochondrial processes, is more readily available for phosphorylating of ${ }^{18}$ F-FDG. However, this possibility contradicts the commonly held view that mitochondrial hexokinase activity using ATP produced in the mitochondria is the most important factor in ${ }^{18} \mathrm{~F}$ FDG incorporation $(22,28)$. 


\section{CONCLUSION}

Dissipation of the mitochondrial membrane potential of tumor cells by treatment with valinomycin enhances ${ }^{18} \mathrm{~F}-$ FDG incorporation, glucose transport, and lactate production but does not affect ATP content, hexokinase activity, or hexokinase subcellular distribution.

\section{ACKNOWLEDGMENTS}

This work was funded by the International Association for Cancer Research (grant 04-300).

\section{REFERENCES}

1. Young H, Baum R, Cremerius U, et al. Measurement of clinical and sub-clinical tumour response using [F-18]fluorodeoxyglucose and positron emission tomography: review and 1999 EORTC recommendations. Eur J Cancer. 1999;35: 1773-1782.

2. van Waarde A, Been LB, Ishiwata K, Dierckx RA, Elsinga PH. Early response of sigma-receptor ligands and metabolic PET tracers to 3 forms of chemotherapy: an in vitro study in glioma cells. J Nucl Med. 2006;47:1538-1545.

3. De Witte O, Hildebrand J, Luxen A, Goldman S. Acute effect of carmustine on glucose metabolism in brain and glioblastoma. Cancer. 1994;74:2836-2842.

4. Maruyama I, Sadato N, Waki A, et al. Hyperacute changes in glucose metabolism of brain tumors after stereotactic radiosurgery: a PET study. J Nucl Med. 1999;40:1085-1090.

5. Spence AM, Muzi M, Graham MM, et al. 2-[F-18]fluoro-2-deoxyglucose and glucose uptake in malignant gliomas before and after radiotherapy: correlation with outcome. Clin Cancer Res. 2002;8:971-979.

6. Fujibayashi Y, Waki A, Sakahara H, et al. Transient increase in glycolytic metabolism in cultured tumor cells immediately after exposure to ionizing radiation: from gene expression to deoxyglucose uptake. Radiat Res. 1997;147: 729-734.

7. Haberkorn U, Reinhardt M, Strauss LG, et al. Metabolic design of combination therapy: use of enhanced fluorodeoxyglucose uptake caused by chemotherapy. J Nucl Med. 1992;33:1981-1987.

8. Haberkorn U, Morr I, Oberdorfer F, et al. Fluorodeoxyglucose uptake in vitro: aspects of method and effects of treatment with gemcitabine. J Nucl Med. 1994;35:1842-1850.

9. Smith TA, Maisey NR, Titley JC, Jackson LE, Leach MO, Ronen SM. Treatment of SW620 cells with Tomudex and oxaliplatin induces changes in 2-deoxy-Dglucose incorporation associated with modifications in glucose transport. $\mathrm{J} \mathrm{Nucl}$ Med. 2000;41:1753-1759.

10. Duijsings D, Houweling H, Vaanerdrager AB, Mol JA, Teerds KJ. Hexadecylphosphocholine causes rapid cell death in canine mammary tumour cells Eur $J$ Pharmacol. 2004;502:185-193.
11. Higashi K, Clavo AC, Wahl RL. In-vitro assessment of 2-fluoro-2-deoxy-dglucose, 1-methionine and thymidine as agents to monitor the early response of a human adenocarcinoma cell-line to radiotherapy. J Nucl Med. 1993;34:773-779.

12. Van de Wiele C, Lahorte C, Oyen W, et al. Nuclear medicine imaging to predict response to radiotherapy: a review. Int J Radiat Oncol Biol Phys. 2003;55:5-15.

13. Furuta M, Hasegawa M, Hayakawa K, et al. Rapid rise in FDG uptake in an irradiated human tumour xenograft. Eur J Nucl Med. 1997;24:435-438.

14. Kroemer G, Reed JC. Mitochondrial control of cell death. Nat Med. 2000;6: $513-519$.

15. Jeong DW, Kim TS, Cho IT, Kim IY. Modification of glycolysis affects cell sensitivity to apoptosis induced by oxidative stress and mediated by mitochondria. Biochem Biophys Res. Commun. 2004;313:984-991.

16. Malka F, Guillery O, Cifuentes-Diaz C, et al. Separate fusion of outer and inner mitochondrial membranes. EMBO Rep. 2005;6:853-859.

17. Poole DT, Butler TC, Williams ME. Intracellulare $\mathrm{pH}$ and glycolysis in ascites tumor cells: effect of membrane-active drugs in potassium depletion. J Natl Cancer Inst. 1972;49:1659-1665.

18. Dimroth P, Kaim G, Matthey U. Crucial role of the membrane potential for ATP synthesis by $\mathrm{F}(1) \mathrm{F}(\mathrm{o})$ ATP synthases. J Exp Biol. 2000;203:51-59.

19. Smith TA, Sharma RI, Thompson AM, Paulin FEM. Tumor F-18-FDG incorporation is enhanced by attenuation of p53 function in breast cancer cells in vitro. J Nucl Med. 2006;47:1525-1530.

20. Salvioli S, Ardizzoni A, Franceschi C, Cossarizza A. JC-1, but not DiOC(6)(3) or rhodamine 123 , is a reliable fluorescent probe to assess delta psi changes in intact cells: implications for studies on mitochondrial functionality during apoptosis. FEBS Lett. 1997;411:77-82.

21. Miccoli L, Oudard S, Sureau F, Poirson F, Dutrillaux B, Poupon MF. Intracellular $\mathrm{pH}$ governs the subcellular distribution of hexokinase in a glioma cell line. Biochem J. 1996;313:957-962.

22. Aloj L, Caraco C, Jagoda E, Eckelman WC, Neumann RD. Glut-1 and hexokinase expression: relationship with 2-fluoro-2-deoxy-D-glucose uptake in A431 and T47D cells in culture. Cancer Res. 1999;59:4709-4714.

23. Santini MT, Romano R, Rainaldi G, et al. H-1-NMR evidence for a different response to the same dose ( 2 Gy) of ionizing radiation of MG-63 human osteosarcoma cells and three-dimensional spheroids. Anticancer Res. 2006;26:267-281.

24. Lutz NW, Tome ME, Cozzone PJ. Early changes in glucose and phospholipid metabolism following apoptosis induction by IFN-gamma/TNF-alpha in HT-29 cells. FEBS Lett. 2003;544:123-128

25. Grande S, Luciani AM, Rosi A, et al. Radiation effects on soluble metabolites in cultured HeLa cells examined by H-1 MRS: changes in concentration of glutathione and of lipid of catabolites induced by gamma rays and proton beams. Int J Cancer. 2001;96(suppl):27-42.

26. Minn H, Kangas L, Knuutila V, Paul R, Sipila H. Determination of 2-fluoro-2deoxy-D-glucose uptake and ATP level for evaluating drug effects in neoplasticcells. Res Exp Med (Berl). 1991;191:27-35.

27. Noda M, Yamashita S, Takahashi N, et al. Switch to anaerobic glucose metabolism with NADH accumulation in the beta-cell model of mitochondrial diabetes. J Biol Chem. 2002;277:41817-41826.

28. Pauwels EKJ, Ribeiro MJ, Stoot JHMB, McCready VR, Bourguignon M, Maziere B. FDG accumulation and tumor biology. Nucl Med Biol. 1998;25: 317-322. 